\title{
Volition in Grammar and Lexical Representation of Verbs: The Case of Kabardian Involuntative
}

\author{
Ranko Matasović
}

\section{Introduction}

The structure of this paper is as follows. In the Introduction, I present some basic typological facts about Kabardian. In section 2, an interesting morphological feature of NW Caucasian languages is presented, and in section 3 it is discussed how this feature should be represented in the grammar. This leads us to some theoretical questions about the status of lexical rules in Role and Reference Grammar and the inter-relationship of features used in the lexical decomposition of verbs in section 4.

Kabardian (or East Circassian) is a NW Caucasian language spoken mostly in the Kabardino-Balkar Republic of the Russian Federation. Like its NW Caucasian relatives (Abkhaz, Abaza, Adyghe, and the extinct Ubykh), it a polysynthetic head-marking language with very little nominal morphology and a very complex verbal system. It has two grammatical cases: absolutive $(-r)$ and ergative $(-m)$; nouns are case marked only when definite, and personal pronouns do not receive case marking; the ergative also marks oblique arguments, such as the recipient (1).

(1) s’āt'a-m džāta-r pśáśa-m yə-h-ā-ś

boy-ERG sword-ABS girl-ERG 3sG.A-carry-PRET-AF

'The boy carried the sword to the girl'1

The verbal complex consists of at least eight prefix slots, followed by the root and at least four suffix slots. Here are the prefix slots: 1. directionals, 2. reflex-

1 My Kabardian examples were drawn from two sources: some were elicited from two informants, Lemma Maremukova and Alim Shomahua, to whom I am very grateful for their help, and others were taken from a collection of Kabardian folk-tales (Nartxer. Adygey epos. Nalchik 1999). 
ive/reciprocal 3. benefactive applicative 4. conjunctivity 5. potential 6. core negation 7. involuntative 8 . causative. Person prefixes can be inserted between these prefix slots (the exact rules for their position are too complex to be discussed here). ${ }^{2}$ The prefix chain is followed by the root and the suffix slots: 1 . detransitivizers 2. tense/evidential 3. mood 4. illocutionary force.

\section{The involuntative in Kabardian}

The Involuntative (Russ. kategorija neproizvol'nosti) indicates that an action is performed unintentionally. It is expressed by the prefix $2 a$ s' $^{\prime}$-, occupying the $7^{\text {th }}$ position in the verbal complex (3).

(2) ś'āla-m dəg $\dot{g}^{w} \partial-r \quad y \partial-w \ni \check{c}^{\prime}-\bar{a}-s$

boy-ERG thief-ABS 3SG.A-kill-PRET-AF

'The young man killed the thief'

(3) s'sāla-m dəg $\dot{g}^{w} \partial-r$ yə-?aśs'a-wəč'āś

boy-ERG thief-ABs 3sG.A-kill-PRET-AF

'The young man (unintentionally) killed the thief'

The only prefix that can occur between the involuntative prefix and the verbal root is the causative prefix $\operatorname{g} a$ - and the person marker indexing the Causer.

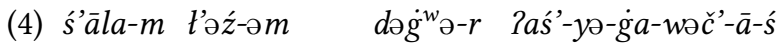

boy-ERG old.man-ERG thief-ABS INVOL-3sG.A-CAUS-kill-PRET-AF

'The boy made the old man accidentally kill the thief' 3

In polite questions, the prefix -?aś' $a$ - can be rendered as "perhaps", or "by chance" (5):

(5) Ц̌ə q’ə-f-2aś'a-mə-łag $\dot{g}^{w}-\bar{a}-w a \quad$ p'ara?

horse DIR-2PL-INVOL-NEG-SEe-PRET-GER INTERROGATIVE

'Haven't you seen a horse, by chance?'

2 For discussion, see my online-grammar of Kabardian (Matasović 2011).

3 Note that, in (4), scope of the involuntative is narrower than the scope of the causative, as the sentence does not mean * "The boy accidentally made the old man kill the thief". This is surprising, since the causative morheme is closer to the root than the involuntative morpheme, so in this case the order of morphemes does not reflect the scope relations of the categories they express. 
It is possible that in examples such as (5) the involuntative morpheme has a special use, partly independent of its other functions. Note that the verb $\operatorname{tag}^{\mathrm{w}}$ ən can be translated as 'to watch' in many contexts, as it usually implies that the act of visual perception is volitional/intentional.

Historically, this prefix is compounded of the noun ?a, 'hand' and the verbal root s'a 'do'. The logic of this is that to do something unintentionally is to do something 'by hand' rather than intentionally, 'by the mind'. Thus, it was originally an incorporated adverbial phrase, but speakers of the language are not aware of this anymore. The involuntative exists in other NW Caucasian languages, including not only Kabardian's closest relative Adyghe (6) (Klimov 1986: 45), but also Abkhaz (7) (Hewitt 1979) and Abaza (8):

(6) $s-? a c ̌ x a-w \partial \check{c} '-a y$

1sGA-INVOL-kill-PRET

'I killed him unintentionally'

(7) $s$-amxa-co-jt'

1SG-INVOL-go-PRET

'I went unwillingly'

(8) s-amxa-хəс̌č $a-t$ '

1SG-INVOL-laugh-PRET

'I laughed unwillingly'

However, the two prefixes expressing involuntative, Kabardian ?aśa- and Adyghe -?ač' $a$ - on the one side, and Abkhaz/Abaza (a)mxa- on the other, are unrelated etymologically. It appears as if the involuntative form developed independently in the two branches of NW Caucasian rather than being inherited from the protolanguage.

\section{What is the Kabardian "involuntative"?}

Languages differ in the way volition is encoded in the meaning of verbs. In most familiar European languages there are special lexical roots for volitional actions, distinguishing them from actions unspecified for volition, e. g. English murder (which is volitional) and kill (which may, but need not be volitional), or watch (volitional) vs. see (unspecified). However, in many Australian languages, 
there is "a single lexeme for a type of activity, irrespective of whether or not it is volitional. There is likely to be one verb which covers both 'fall over', which is non-volitional, and 'throw oneself to the ground', which is volitional. Some languages have a single verb covering both 'ignore (someone or something)', a volitional activity, and 'lose (something)', which is non-volitional; and some have one verb covering 'hide' (volitional) and 'lose' (non-volitional)” (Dixon 2002: 57).

In Bats (or Tsova-Tush), many intransitive verbs are unspecified for volition and occur with different case-frames and person/number suffixes depending on the intentionality of their single core argument (or "Subject”, Holisky 1987):

(9) (As) vuiž-n-as

1SG.ERG fall-PRET-1SG.ERG

'I fell down (on purpose)'

(10) (So) vož-en-sö

1sG.ABS fall-PRET-1sG.ABS

'I fell down (accidentally)'

In (9), the subject is volitional, and it is marked by different case-marking and person suffix on the verb than in (10), where the subject is non-volitional.

Finally, in some languages, verbs exhibiting the volitional/non-volitional opposition have the volitional meaning by default. In Japanese, verbs corresponding to English 'kill', 'break', or 'throw' imply that their subject acted intentionally, so that literal translations of sentences like "John accidentally killed the dog", or "Joan unintentionally broke the eye-glasses" (11) are ungrammatical. Rather, one must use a special construction with the verb simaw- 'put' (12) in order to get the desired meaning (Van Valin \& LaPolla 1997: 118-120):

(11) * Zyoon wa ukkari-to megane o wat-ta

Joan TOPIC unintentionally glasses ACC break-PRET

'Joan unintentionally broke the eye-glasses'

(12)

Zyoon wa ukkari-to megane o wat-te simat-ta

Joan TOPIC unintentionally glasses ACC break-LINKER put-PRET 'Joan unintentionally broke the eye-glasses'

In terms of Role and Reference Grammar, this means that languages differ considerably in the ways they lexicalize Agenthood. In discussing volition in grammar 
of any language, one has to establish whether volition characterizes the meaning of the verb itself, or rather the relation of the verb and one of its arguments, presumably the Actor. In the latter case, the verb expresses the will, or desire of the subject that the action or state it denotes be fulfilled, and we are dealing with a grammatical mood, which is usually called the optative. Such a mood exists, e. g., in Classical Greek:

(13) õ paĩ, gén-oio

patr-òs

eutykh-éstero-s

o boy.voc become-2SG.OPT.MID. father-GEN.SG. fortunate-COMP.-NOM.SG.

'O boy, may you prove more fortunate than your father' (Sophocles, Aj. 550)

The optative form in (13) expresses the will, or desire of the speaker, but the verb (génesthai 'to become') does not, by itself, lexicalize the will or volitionality (it is not a part of the verb's meaning).

Other languages have different modal forms for expressing volition, e. g. the purposive form which exists in several Australian languages, including Warrongo (Tsunoda 2011: 292):

(14) malan-da nyola yodi-yal goyay-ngaL

river-LOC 3SG.NOM swim-PURP across-to

'She intended to swim across a river'

In Role and Reference Grammar, mood markers are represented as operators on the Core of the sentence. However, evidence is plentiful that the involuntative in Kabardian should not be treated as a mood. Mood and modality markers are generally suffixes in Kabardian. The following examples show how the admirative, optative, and permissive moods are formed and used.

The admirative:

(15) sa nawba zə məśa s-łag $\dot{q}^{w-} \bar{a}-s^{-} y \partial$

I today 1 bear 1sG.A-see-PRET-AF-ADM.

'Why, I saw a bear today!'

The optative:

(16) $\bar{a}-r \quad q$ 'a-səžā-śara(t)

he-ABS DIR-come-OPT

'Oh if he would come!' 
The permissive:

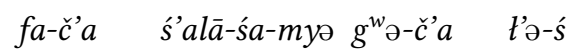

skin-INST boy-AF-PERM heart-INST man-AF

'Although by skin (=judging by the skin) he is a boy, by heart he is a man'

Clearly, then, the "involuntative" does not pattern like the other moods in Kabardian.

If volition characterizes the nature of the action expressed by the verb, then, if it is expressed by an affix, it cannot be represented as a Core operator. Since it characterizes the Nucleus, we might consider introducing a Nuclear operator expressing volition (or the absence of volition). The involutative marker would be parallel to aspectual markers, which are also represented as Nuclear operators in RRG in languages that have aspect as a grammatical category.

A different possibility is to claim that the function of the involuntative prefix ?aś' $a$ - is to change the logical structure of the verb, and within the framework of Role and Reference grammar this can only mean that it is used to cancel the Agent in the logical structure of the verb. ${ }^{4}$ In RRG, this rule would be represented as follows (for intransitive verbs):

DO $\left(\mathrm{x}, \mathbf{d o}^{\prime}\left(\mathrm{x},\left[\operatorname{pred}^{\prime}(\mathrm{x})\right]\right) \rightarrow\right.$ do' $\left.^{\prime}\left(\mathrm{x},\left[\operatorname{pred}^{\prime}(\mathrm{x})\right]\right)\right)$

There are two reasons to think that this second hypothesis is preferable. Firstly, introducing a new type of operator into the theory is clearly less economical than analyzing the involuntative in terms of lexical rules affecting the logical structure of verbs, which are posited by RRG in any case, and which are independently motivated in the theory.

Secondly, operators are usually used to express grammatical categories, i.e. they belong to the domain of inflection rather than derivation. Yet the involuntative in Kabardian is clearly a derivational rather than inflectional category. It shares at least seven of the 11 features that may be used to distinguish derivation

${ }^{4}$ It would, in principle, be possible to add an operator INVOL ('Involuntative') to the stock of RRG operators and claim that adding the involuntative prefix in Kabardian can be represented as adding of that operator to the logical structure of a verb. This would imply that the prefix ?aś' $a$ - can be added only to verbs that are lexically not specified as agentive or volitional (i. e. that it cannot be added to the equivalents of English 'murder' or 'watch') but, as will be shown below, quite the opposite generalization seems to obtain in Kabardian: ?as' $a$ - may be added only to inherently agentive/volitional verbs to cancel this part of their meaning. 
from inflection (Aikhenvald 2007: 36): 1. It is clearly optional (verbs do not have to be inflected for volition, as they do for, e.g., person). 2. The prefix expressing the involuntative is closer to the root than prefixes expressing inflectional categories 3. It is specific to a single word class (verb). 4. It adds a semantic specification to a root (without changing word class). 5. It does not participate in agreement. 6. Its frequency of occurrence is much lower than that of inflectional categories (such as tense, person, or number), and 7. it is expressed by a bisyllabic affix, whereas nearly all of the inflectional prefixes in Kabardian are monosyllabic.

The prefix ?aśa- cannot be used with all the verbs in the language, but the exact restrictions on its use are still quite obscure. The first thing to note is that it is generally incompatible with stative verbs (18-19):

(18) s'sāla-r šantə-m tay-s-ś

boy-ABS chair-ERG DIR-sit-AFG

'The boy sits on the chair'

(19) *śālam šantəm ?aś'a-tay-s-ś

'The boy accidentally sits on the chair'5

However, the involuntative can be used with a number of transitive stative verbs of cognition and perception (20-21):

(20) śāla-m pśāśa-r yə-łā $\dot{g}^{w}-\bar{a}-\dot{s}$

boy-ERg girl-ABs 3sG.A-see-PRET-AF

'The boy saw the girl' (also 'The boy watched the girl')

(21) śāla-m pśāśa-r yə-?aś'a-tā $\dot{g}^{w}-\bar{a}-s$

boy-ERG girl-ABs 3SG.A-INVOL-see-PRET-AF

'The boy accidentally spotted the girl'

A reasonable hypothesis would be that the involuntative is restricted to Activity verbs that are specified for Agenthood in their lexical representation. And indeed,

5 The example (19) is ungrammatical rather than just infelicitous, as my informants do not think there could be any circumstances in which one would utter such a sentence (e. g. if someone accidentally sat on a chair not reserved for him/her in a theater).

6 Kabardian has only one verb corresponding to English 'watch' and 'see', tag $^{\text {'w }}$ ən. In most contexts the translation 'to see' is appropriate, but the implication is always that seeing/watching is volitional (see also the example (5) above). 
there appear to be quasi-synonymous verbs that seem to differ only in that one has the Agent in in its lexical representation, while the other one does not.

For example, the verb txalən 'strangle, kill by biting or cutting the throat' cannot be modified by the involuntative prefix ?aś' $a$-:

(22) *ha-m bāža-r yə-?aśa-txal-āaśs

dog-ERG foX-ABS 3SG.A-INVOL-kill-PRET-AF

'The dog killed (strangled) the fox unintentionally'

However, an intransitive verb derived from the same root, txaləhən 'kill (by biting the throat)', may be modified by the involuntative (23):

(23) ha-r bāža-m Raśa-txaləh-ā-śs

dog-ABS fOX-ERG INVOL-kill-PRET-AF

'The dog killed the fox (unintentionally)'

Another indication that the verbs that may take the involuntative prefix contain the Agent in their logical structure comes from their incompatibility with adverbial expressions such as yəməś' axxawə 'unintentionally'. The verb wəč'ən'kill' which may be modified by the involuntative prefix in (3) above, cannot be combined with the adverbial yəməśaxxawə (24):

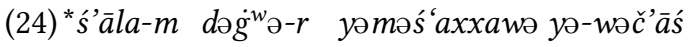

boy-ERG thief-ABS not.wanting 3SG.A-kill-PRET-AF

'The boy unintentionally killed the thief'

Thus, it appears probable that verbs to which ?as'a- can be added always include the Agent argument in their logical structure. The adding of the involuntative prefix changes the logical structure of the verb by cancelling the agentivity of the verb.

Our analysis predicts that the reverse lexical rule also applies in some languages, i. e. that there are languages in which the Agent can be added to the lexical representation of a verb, thus expressedly characterizing its action as volitional. And indeed, in Amis (Austronesian, Taiwan) we find a suffix (-en) which adds the Agent to the lexical representation of activity verbs, while also making them active accomplishments (Wu 2006: 175-177): 
(25)

Ca'ay $k$ - $u$ pataduan $n-i \quad$ aki mi-curah $t$-u lumaq NEG-NOM-CN intention GEN-PPN Aki AV-burn DAT-CN house 'It is not Aki's intention to burn the house.'

(26) ${ }^{*}$ Ca'ay $k-u$ pataduan $n-i \quad$ aki curah-en $k-u \quad$ lumaq NEG NOM-CN intention GEN-PPN Aki burn-UV NOM-CN house 'It is not Aki's intention to burn the house'
Patay-en k-u-ra 'oner! dead-uv NOM-CN-that snake 'Kill that snake!' (the subject must be human)

In (25), with the Active Voice prefix mi-, the sentence is grammatical, showing that the verb curah 'burn' is compatible with unintentional agents. However, the use of the suffix - en in (26) would make the unintentional reading impossible, hence the sentence is ungrammatical. Example (27) shows the regular use of the suffix -en, which can only be combined with human, intentional agents. According to $\mathrm{Wu}$ (2006: 177) "When suffixed to an activity verb [the suffix -en] derives an agentive active accomplishment. The agentive component DO explains why this suffix can only appear with [+human] effector, and why it cannot appear with expressions such as "unintentionally"'. Volitionals (or voluntatives) are also reported for some Native American languages - including Klamath and Shasta (Mithun 1999: 450, 499), Chalcatongo Mixtec (Macaulay 1996: 76-78), in the Papuan language Makalero (Huber 2011: 479), and presumably elsewhere. It remains unclear to what extent these formations are the reverse of the Kabardian involuntative, i. e. whether they can be characterized as adding the Agent to the logical form of the verb.

Lexical rules for adding and deleting the Agent in the lexical representation of a verb can sometimes result in zero-affixation, i. e. the operation of the rule does not need to be visible in the morphology. This is the case in Bats (TsovaTush), as we saw above. In that language Agentivity is highly grammaticalized, but there is no special suffix for involuntative action, or cancelling of the Agent. In that language, we would say that there is a lexical rule adding (or removing) the Agent from the lexical representation of activity verbs, and the difference in the examples (9) and (10) would be handled by rules of case assignment: the Ergative case is assigned to the Agent argument and the Absolutive to the nonAgent macrorole of intransitive verbs. 


\section{The broader perspective: operations that cancel parts of the logical structure of verbs}

If we agree that adding the involuntative prefix in Kabardian can be represented by a lexical rule, the question arises why this particular type of lexical rule is so rare cross-linguistically. This brings us to the issue of roles played by lexical rules in linguistic theory, and in particular in Role and Reference Grammar. The basic assumption of Role-and-Reference Grammar is that lexical rules operate on logical structures of verbs, which are essentially based on the Aktionsarten and the semantic features that define them. Here is the list of the Aktionsarten posited in RRG (Van Valin 2005: 33):

State: pred'(x), ${ }^{7}$ e. g. Fohn is ill

Activity: do'(x) [pred'(x)], e.g. John walks

Achievement: INGR pred'(x), e.g. The baloon popped

Semelfactive: SEML pred'(x), e. g. The light flashed.

Accomplishment: BECOME pred'(x), e. g. The ice melted. ${ }^{8}$

Active accomplishment: do'(x, $\left.\left[\operatorname{pred}_{1}{ }^{\prime}(\mathrm{x}, \mathrm{y})\right]\right)$ \& INGR $\operatorname{pred}_{2}{ }^{\prime}(\mathrm{y})$, e. g. Dana ate the fish.

All Aktionsarten have their causative variants, represented with the operator CAUSE, e. g. kill ([do' (x,0)] CAUSE BECOME [dead' (y)]) is the causative accomplishment derived from the accomplishment die BECOME [dead'(x)]. Moreover, there is a special operator DO that characterizes activity verbs that have an Agent (conscious and willful instigator of an action) in their logical structure, as we saw in the preceding sections.

Van Valin (2005: 41) notes that some patterns of operations cancelling parts of the logical structure of verbs are very common cross-linguistically. In many languages we find a pattern relating states, accomplishments, and causative accomplishments, as illustrated by Van Valin's examples from Yagua, French, and Russian:

7 This is, of course, the representation of a single-argument predicate (or intransitive verb). Other Aktionsarten are also mostly represented by intransitive verbs.

8 The operator BECOME is actually not a primitive. It is composed of the operator PROC (for 'process') and the operator adding telicity (INGR), but in many languages, including English, BECOME may be used as a shorthand for PROC... \& INGR. 
Causative accomplishment Accomplishment State

(28) Yagua -muta- 'open [TR]' -muta-y- 'open [INTR]' muta-y-maa 'be open'

(29) French briser 'break [TR]' se briser 'break [INTR]' brisé 'broken'

(30) Russian razbit' 'break [TR]' razbit'sja 'break [INTR]' razbitij 'broken'

This pattern can be easily represented as cancelling of the operator CAUSE (i), ${ }^{9}$ to make an accomplishment from a causative accomplishment, and the subsequent deletion of the operator BECOME (ii) to make a state predicate from an accomplishment.

(i) $\left[\right.$ do' $\left.^{\prime}(\mathrm{x}, 0)\right]$ CAUSE $[\mathrm{BECOME}$ pred' $(\mathrm{y})] \rightarrow$ BECOME [pred'(y)]

(ii) BECOME pred'(x) $\rightarrow$ pred'(x)

So, perhaps this pattern of lexical rules is so common because of the fact that it involves the consecutive cancelling of a single feature from the logical structure of the verb. We can point out that there are other patterns that seem to be rather well-attested in the languages of the world, such as those relating Active Accomplishments to states (31) and to Activities (32, 33), as well as those deriving Activities (34) and Accomplishments (35) from States:

(31) Chukchi: vak?o-k 'adopt a sitting position': vak?o-tva-k 'sit': do'(x) \& INGR pred'( $\mathrm{x}) \rightarrow$ pred'(x) (Active Accomplishment $\rightarrow$ State, cf. Comrie (1985: 342)

(32) Georgian: c'er 'write' : da-c'er 'write' (completely): do'(x) pred'(x,y) $\rightarrow$ do'(x) pred'(x,y) \& INGR pred'(y) (Activity $\rightarrow$ Active Accomplishment)

(33) Lithuanian: pa-skusti 'clean' (completely) : pa-skut-ine-ti 'clean' : do'(x) pred'(x,y) \& INGR pred'(y) $\rightarrow$ do'(x) pred'(x,y) (Active Accomplishment $\rightarrow$ Activity)

(34) English: Fohn is stupid: fohn is being stupid: pred'(x) $\rightarrow$ do'(x) pred'(x) (State $\rightarrow$ Activity)

(35) German: gebrochen 'broken' : wurde gebrochen 'has been broken' : pred'(y) $\rightarrow$ BECOME pred'(y) (State $\rightarrow$ Accomplishment)

9 The approach of Role and Reference Grammar runs contrary to the "Monotonicity Hypothesis", according to which word formation operations do not delete operators from lexical representations. See Koontz-Garboden (2009) for an account of de-causativization in Spanish that argues for the "Monotonicity Hypothesis". 
As we see from examples (34) and (35), lexical rules changing the lexical representation of verbs need not be expressed through affixation - they can also be expressed in certain syntactic constructions, or, in other words, constructions may affect the lexical representation of verbs by adding or cancelling elements of their meaning. Obviously, then, many languages have mechanisms for derivation of different Aktionsarten by adding or cancelling parts of logical structures of verbs, but it is still intriguing that some patterns are much more common than others, and there are some patterns that may not be attested at all. For example, why don't we find languages which derive statives, or activities from semelfactives by cancelling the operator SEML?

*SEML pred'(x) $\rightarrow$ pred'(x)

*SEML do'(x, [pred'(x)] $\rightarrow$ pred'(x)

Likewise, there do not seem to be any languages in which accomplishment predicates are derived directly from achievement predicates, or vice versa:

*BECOME pred'(x) $\rightarrow$ INGR pred'(x)

${ }^{*}$ INGR pred'( $\left.\mathrm{x}\right) \rightarrow$ BECOME pred'( $\left.\mathrm{x}\right)$

So, why are some types of lexical rules more common than others? The first thing to note is that, generally, lexical rules cancelling parts of the logical structure of verbs seem not to be less common than lexical rules deriving more complex structures from simpler ones. For example, causatives are just as common, cross-linguistically, as de-causatives. ${ }^{10}$ There appears to be no cross-linguistic bias towards iconicity here, so that elements in the logical structure should generally be expressed by affixes. Affixes can just as easily express the absence of an element in the logical structure, e. g. the absence of the CAUSE operator. As Haspelmath puts it, "Variation in the direction of formal derivation can generally be seen as the manifestation of indeterminacy of the conceptual-semantic relation" (Haspelmath 1993: 90). Causative accomplishments are "objectively" more complex than (simple) accomplishments, but that does not mean that this relation must be conceptualized (and lexicalized) in every language so that the former must be derived from the latter by causativization. Indeed, it must not, as we have seen. However, the existence of bi-directional patterns of derivation

\footnotetext{
${ }^{10}$ Nichols et al. (2004) examine 80 languages with respect to valence-increasing and valence decreasing operation. They note that the "reduced" type of valency decreasing (decausativization by means of an affix) is correlated with morphological complexity.
} 
shows that the conceptual-semantic relation exists and that it can be subject to lexical rules.

It transpires from the discussion so far that the types of lexical rules are constrained by two parameters: (1) the frequency of lexicalization of certain concepts, which is the consequence of the overall structure of human cognitive system and the nature of our everyday experiences, and (2) the conceptual distance, measured by the number of shared semantic features, between different types of verbal meanings (or Aktionsarten).

The first parameter has to do with economy: certain types of meanings are rarely conceptualized and lexicalized cross-linguistically. This is the case with the change that involves cancelling the Agent, as in the Kabardian "involuntative": languages apparently never have more than a handful of verbs that have the Agent as part of their logical structure, and it would be uneconomical to have a productive lexical operation for cancelling it, if such a rule applied to just a few verbs. Similarly, semelfactive meanings appear to be lexicalized quite rarely (which is why this Aktionsart was not noted in earlier versions of RRG, for example in Van Valin \& LaPolla 1997), so having an affix for cancelling semelfactive meanings would be uneconomical. ${ }^{11}$

The second parameter has to do with conceptual differences between different Aktionsarten. In order to measure those differences, we represent the Aktionsarten as sets of features, or semantic primitives. The number of features defining particular Aktionsarten differs, and only those that differ in the presence of a single feature can be easily related by cross-linguistically common lexical rules. The system of features that define the Aktionsarten should be as simple as possible, i. e. we should posit no more features than are needed to derive all six primary Aktionsarten (Semelfactives, States, Accomplishments, Achievements, Activities and Active Accomplishments) plus the two secondary ones (Causatives and Agentive verbs). Here we propose a system of features that is slightly different from the one established in the RRG literature (Van Valin \& LaPolla 1997, Van Valin 2005): ${ }^{12}$

${ }^{11}$ In languages which do have affixes glossed as semelfactives, e. g. the Athabaskan languages, these can be added to verbal stems expressing activities. However, they generally do not mean that an action should be conceptualized as instantaneous, but rather that the action is performed only once, e. g. Koyukon yeel-t'ut 'she cut it once' (Axelrod 1993: 73-76).

${ }^{12}$ We do not include the feature [+static], as it cannot be combined with any other feature, unlike the feature [+duration], which serves to distinguish two classes of Aktionsarten. Note also that states 
Semelfactives: [-duration, $+/$-(internal) force, -telicity]

States/processes: [+duration, -(internal) force, -telicity]

Accomplishments: [+duration, -(internal) force, +telicity]

Achievements: [-duration, +(internal) force, +telicity]

Activities: [+duration, +(internal) force, -telicity]

Active accomplishments:] [+duration, +(internal) force, +telicity]

Agentive verbs: [+volition, $+($ internal) force... ]

Causatives: [+external force, $+($ internal) force...]

The feature [+external force] can be added to all lexical representations to derive the causatives, and the cancelling of that feature would be the equivalent of de-causativization. The feature [+volition], if added to lexical representations characterized by the feature [+force] (i. e. to causatives, activities and active accomplishments) derives agentive verbs from their non-agentive counterparts. The advantage of this system lexical representation is that it operates with features which are independently known to play a significant role in cognitive psychology (telicity, force, and time/duration), and that Aktionsarten that appear to be rarely involved in lexical rules (Semelfactives and Achievements) are separated from the rest in the hierarchy in that they differ in the primary feature [+/-duration]. This should also explain why accomplishments and achievements rarely enter into relationships by means of lexical rules. They differ in two features (duration and internal force) and agree in only one (telicity), so any rule by which one would be derived from the other would have to simultaneously cancel or add two different features.

It is clear from our discussion that all features do not have the same status, but that there is rather a hierarchical organization of features that should be captured by the theory.

An advantage of this system is also that it is hierarchical, so that it reflects our intuition that not all Aktionsarten have equally complex semantic represen-

and processes are not easily distinguishable, and should be probably treated as involving a single feature: what they have in common is that they lack the concept of internal or external force that is involved in other kinds of events. Thus we would say that both being dead and being heavy (states) share the same feature with revolving, flowing, and getting old (processes) because none of those events are conceptualized as result of the application of force. Processes are, in essence, a particular kind of states that cannot be divided into identical parts or periods, e. g. "being white" is a state, and all parts or stages of that state are identical. "Getting old" is a process, hence different stages of that process are not identical. 


\section{References}

tation. As a first approximation, we can start with the following representation of features and Aktionsarten. Let us call it the Aktionsart Hierarchy:

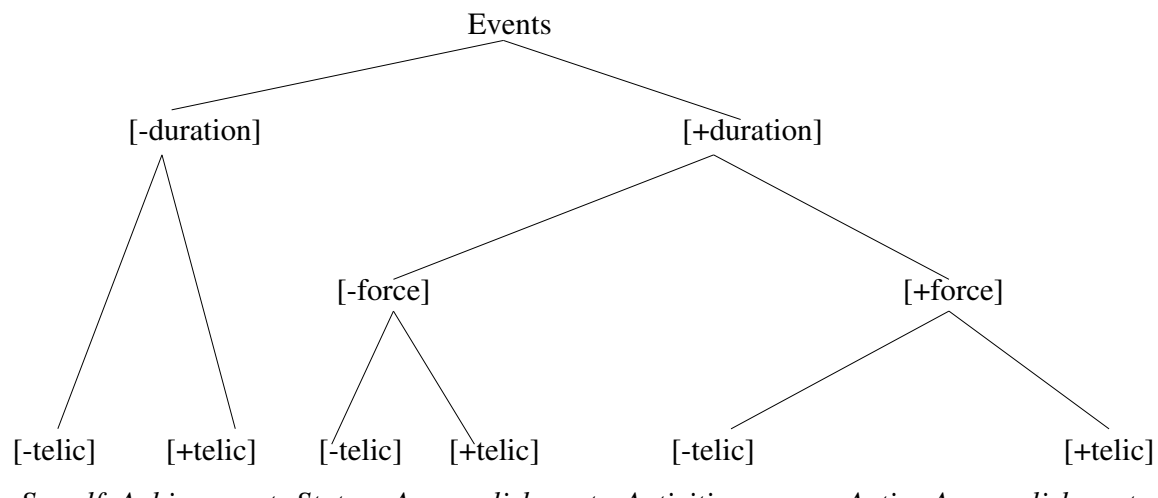

Semelf. Achievements States Accomplishments Activities

Active Accomplishments

We would predict that those Aktionsarten that are located in different primary branches will be less often related by lexical rules, especially the Aktionsarten that differ in the feature [+duration] and [-duration]. Whether this prediction is borne out by the fact should be established on the basis of a thorough typological investigation, which is beyond the scope of this paper.

\section{Abbreviations used}

$\begin{array}{lll}\text { A = AGENT } & \text { GEN = GENITIVE } & \text { PERF = PERFECT } \\ \text { ABS = ABSOLUTIVE } & \text { GER = GERUND } & \text { P = PATIENT } \\ \text { ADM = ADMIRATIVE } & \text { INVOL = INVOLUNTATIVE } & \text { PERM = PERMISSIVE } \\ \text { AF = AFFIRMATIVE } & \text { LOC = LOCATIVE } & \text { PPN = PERSONAL PROPER NOUN } \\ \text { AV = ACTOR VOICE } & \text { MID = MIDDLE } & \text { PRET = PRETERITE } \\ \text { CAUS = CAUSATIVE } & \text { N = NEUTER } & \text { PURP = PURPOSIVE } \\ \text { CN = COMMON NOUN } & \text { NEG = NEGATION } & \text { REFL = REFLEXIVE } \\ \text { COMP = COMPARATIVE } & \text { NOM = NOMINATIVE } & \text { SG = SINGULAR } \\ \text { DIR = DIRECTIONAL } & \text { OBL = OBLIQUE } & \text { UV = UNDERGOER VOICE } \\ \text { F = FEMININE } & \text { OPT = OPTATIVE } & \end{array}$

\section{References}

Aikhenvald, A. 2007. Typological distinctions in word-formation. In T. Shopen (ed.), Language typology and syntactic Description, III: Grammatical categories 
and the lexicon, 1-65. Cambridge: Cambridge University Press.

Axelrod, M. 1993. The Semantics of time. Aspectual categorization in Koyukon Athabaskan, Lincoln: Nebraska University Press.

Colarusso, J. 1992. A grammar of the Kabardian language. Calgary: University of Calgary Press.

Comrie, B. 1985. Causative verb formation and other verb-deriving morphology. In T. Shopen (ed.). Language typology and syntactic description, III, 309-347, Cambridge: Cambridge University Press.

Dixon, R. M. W. 2002. Australian languages. Cambridge: Cambridge University Press.

Haspelmath, M. 1993. More on the typology of the inchoative/causative verb alternation. In B. Comrie \& M. Polinsky (eds.). Causatives and transitivity, 87120. Amsterdam: John Benjamins.

Hewitt, G. 1979. Abkhaz. London: Croom Helm.

Holisky, D. A. 1987. The case of the intransitive subject in Tsova-Tush (Batsbi). Lingua 71: 103-132.

Huber, J. 2011. Makalero. A Papuan language of East Timor. Utrecht: LOT.

Klimov, G. 1986. Vvedenie v kavkazskoe jazykoznanie. Moscow: Nauka.

Koontz-Garboden, A. 2009. Anticausativization. Natural Language \& Linguistic Theory 27: 77-138.

Macaulay, M. 1996. A grammar of Chalcatongo Mixtec. Berkeley: The University of California Press.

Matasović, R. 2011. A grammar of East Circassian (Kabardian). http://www.ffzg .hr/ rmatasov.

Mithun, M. 1999. The languages of native North America. Cambridge: Cambridge University Press.

Nichols, J., D. A. Petersen \& J. Bernes. 2004. Transitivizing and detransitivizing languages. Linguistic Typology 8: 149-211.

Piñón, C. 2002. A finer look at the causative-inchoative alternation. Manuscript - Heinrich-Heine University, Düsseldorf.

Tsunoda, T. 2011. A grammar of Warrongo. Berlin: Mouton de Gruyter.

Van Valin, R. D., Jr \& R. LaPolla. 1997. Syntax. Structure, meaning and function. Cambridge: Cambridge University Press.

Van Valin, R. D., Jr. 2005. Exploring the syntax-semantics interface. Cambridge: Cambridge University Press. 


\section{References}

Wu, J. 2006. Verb classes, case marking and grammatical relations in Amis. Ph.D. Thesis, SUNY Buffalo, http://linguistics.buffalo.edu/people/faculty/vanvalin/ rrg.html.

\section{Author}

Ranko Matasović

University of Zagreb

rmatasov@ffzg.hr 
